\title{
IDENTIFICAÇÃO DE OPORTUNIDADES DE MELHORIA DE DESEMPENHO AMBIENTAL EM PROCESSO DE PRODUÇÃO DE MATERIAIS CERÂMICOS VIA APLICAÇÃO DA TÉCNICA DE AVALIAÇÃO DE CICLO DE VIDA (ACV)
}

\section{IDENTIFICATION OF ENVIRONMENTAL PERFORMANCE IMPROVEMENT OPPORTUNITIE IN A MATERIAL CERAMICS PRODUCTION PROCESS BY LIFE CYCLE ASSESSMENT (LCA) APPROACH APPLYING}

\author{
Adriana Petrella Hansen*adriana.phansen@gmail.com \\ Emilia Satoshi Miyamaru Seo*esmiyseo@ipen.br \\ Luiz Alexandre Kulay*luiz.akulay@sp.senac.br \\ ${ }^{*}$ Centro Universitário SENAC
}

\begin{abstract}
Resumo: O segmento de construção civil é considerado - dentre as ações antrópicas - como de grande importância em termos de socioeconômicos para a sociedade moderna. Por outro lado, esse ramo de atividade se consagra também por proporcionar, quase que na mesma escala de magnitude, significativos impactos sobre o meio ambiente, tanto em termos de consumo de recursos como de geração de rejeitos. Nesse contexto, o presente estudo se propõe a elaborar o perfil ambiental do processo de fabricação de cerâmica de revestimento via úmida, especificamente de porcelanatos, a fim de permitir a proposição de técnicas de engenharia e de gestão ambiental que resultem na redução dos impactos ambientais correspondentes ao mesmo. Tais objetivos foram alcançados a partir da aplicação de uma ferramenta de gestão ambiental de amplitude sistêmica e foco sobre a função denominada Avaliação do Ciclo de Vida (ACV). Os impactos ambientais mais significativos consistem dos potencias de aquecimento global e da toxicidade humana. Verificou-se que tais impactos ambientais decorrem do consumo de gás natural e do transporte utilizado para a locomoção das matérias-primas. $O$ desenvolvimento de medidas que tornem mais eficiente à geração de ar, que reduzam a perda de material no processo, que aperfeiçoem os parâmetros operacionais, ou que visem à substituição do combustível para fontes mais limpas, bem como a revisão do transporte de insumos são ações de redução com potencial para melhorar o perfil ambiental analisado.
\end{abstract}

Palavras chaves: Porcelanato Esmaltado. Avaliação do Ciclo de Vida. Produção mais Limpa. Setor Cerâmico.

Abstract: The building sector is considered - among human actions - as of great importance in terms of socioeconomic to modern society. Moreover, this class of activity is also supposed to provide, significant environmental impacts related to natural resource consumption and waste disposal. In this context, this study proposes to examine the environmental profile of the manufacturing process of ceramic tile wet, in order to make propositions techniques that result in reduction of environmental impacts provided by him. After this stage, made the proposition to Cleaner Production activities aimed at minimizing these environmental constraints. These objectives were achieved from the application of an environmental management tool amplitude and systemic focus on the function called Life Cycle Assessment (LCA). The most significant environmental impacts consist of potential global warming and human toxicity. It was found that such environmental impacts resulting from the consumption of natural gas and transport used for transportation of raw materials. The development of measures to become more efficient at generating hot air, reducing the loss of material in the process, to improve

Revista Produção Online, v.10, n.4, p. 912-936, dez., 2010 
their operational parameters, or to provide for the replacement of fuel to cleaner sources, such as a review of the transport of inputs are reduction actions with the potential to improve the environmental profile analysis.

Key words: Enamel porcelain. Life Cycle Assessment. Cleaner Production. Ceramic Sector.

\section{INTRODUÇÃO}

Ao conscientizar-se de que a produção de bens de consumo afeta de maneira adversa o suprimento de recursos naturais e a qualidade do ambiente, a sociedade passou a questionar firmemente o Modelo Desenvolvimentista, amplamente praticado pelo meio empresarial ao longo dos anos de 1970, como forma de satisfazer as necessidades do ser humano moderno.

Como resposta a esta manifestação, muitas corporações procuram atuar sobre seus respectivos processos de transformação - dentro dos limites permitidos pela tecnologia à época existente - buscando reduzir impactos ambientais deles decorrentes. De maneira inexorável - ainda que legítima - essas ações não se propunham a manter um equilíbrio dinâmico entre a atividade antrópica e seu entorno, mas sim, a preservar - ou até e desejavelmente, conquistar - posições dentro de um mercado cada vez mais competitivo. Desta abordagem, decorreram de inicio ações de controle e - mais recentemente, ações de prevenção da poluição.

As ações de controle se mostraram fundamentais em primeira instância pelo fato de atribuir políticas ambientais, surgindo concomitantemente legislações especializadas no tema, padrões de controle e tecnologias próprias para a redução de impactos sobre o meio ambiente.

A chamada política de comando e controle não tinha, porém, jurisdição direta sobre as etapas de pós-produção de produtos - caso de uso e disposição final além de não gerar padrões de controle para muitas das atividades antrópicas, sobretudo no segmento de serviços. Não obstante, as grandes corporações começaram lentamente a perceber que um sistema produtivo mais enxuto, com diminutos consumos e produção de rejeitos, seria mais rentável. Iniciava-se nesse momento o sistema de gestão ambiental voltado à prevenção da poluição (VILELA; DEMAJOROVIC, 2006). 
Tais medidas de prevenção da poluição buscam atuar no agora chamado ciclo de vida de um produto que se estende desde a extração de recursos naturais para a produção do bem, até sua disposição final, quando a função para a qual o mesmo foi concebido se houver encerrado e se nenhuma outra puder ser cumprida a partir deste mesmo insumo.

No ciclo produtivo, tal abordagem tem ação direta, enquanto que, sobretudo, na etapa de uso, esta se apresenta no nível de recomendação ao consumidor.

Dentro do contexto de prevenção da poluição, o presente trabalho visa elaborar o perfil ambiental do processo de fabricação de cerâmica de revestimento via úmida, especificamente de porcelanatos, a fim de permitir a proposição de técnicas de engenharia e de gestão ambiental que resultem na redução dos impactos ambientais correspondentes ao mesmo.

Para tanto, dada a amplitude de abordagem, sistêmica por essência, e o grau de aprofundamento quanto à avaliação das inter-relações entre o meio ambiente $e$ os sistemas humanos, será adotado como mecanismo de análise, uma das ferramentas mais efetivas da gestão ambiental: a Avaliação do Ciclo de Vida (ACV), a qual será aplicada para fins de identificação dos pontos potenciais de melhoria de desempenho ambiental do processo.

Para dar conta disso a iniciativa estrutura-se em dois objetivos específicos, que são complementares entre si. O primeiro deles consiste em realizar uma avaliação do processo de produção do produto cerâmico em estudo de abrangência "berço-ao-portão da fábrica".

O segundo objetivo visa à elaboração de um diagnóstico com envergadura e nível de detalhe suficiente para permitir a proposição de soluções nos níveis técnicos - ou seja, de engenharia, de gestão, de Produção mais Limpa $(P+L)$, entre outros - e comportamental - via treinamento, capacitação, formação de competências específicas, e afins - a fim de melhorar o desempenho ambiental dos mesmos produtos. 


\section{AVALIAÇÃO DO CICLO DE VIDA: GENERALIDADE, USOS E LIMITAÇÕES DA TÉCNICA}

O reconhecimento dos limites da exploração de recursos naturais e da capacidade de suporte do meio ambiente em incorporar os rejeitos das atividades antrópicas desencadeou, em meados da década de 1970, em um movimento da indústria para a implementação de medidas de controle ambiental.

Esta percepção, fundamentada essencialmente na crise de petróleo e no crescimento expressivo da população mundial na década de 1960, acabou por impulsionar não somente um questionamento sobre o consumo de bens escassos como também sobre os impactos ocasionados pela poluição.

Neste contexto, em 1969, foi realizado o primeiro estudo com vistas a inventariar o desempenho ambiental de um produto. Tal trabalho, desenvolvido para a Coca-Cola Co e inicialmente denominado Resource Enviromental Profile Analysis (REPA), levantou os consumos de energia e materiais do processo da fabricação das embalagens utilizadas para acondicionamento do refrigerante, a fim de selecionar aquela com melhor desempenho ambiental (MOURAD et. al, 2002).

A conscientização da sociedade por um desenvolvimento sustentável e a busca pelo aumento do desempenho ambiental das organizações estimulou, assim, a evolução de uma linha de pensamento capaz de avaliar o saldo ambiental de produtos e serviços, por meio de uma abordagem ampla das inter-relações entre os sistemas e o meio ambiente.

Constitui-se, desta forma, como ferramenta de suporte à gestão a técnica de Avaliação do Ciclo de Vida (ACV). Segundo Vilela; Demajorovic (2006) a ACV pode ser entendida como uma técnica de avaliação quantitativa, voltada à determinação de impactos ambientais associados ao exercício da função de um produto, processo ou serviço.

Tendo em vista o fato de seu escopo de aplicação ser sistêmico, ou seja, compreender todas as ações antrópicas desde a extração junto ao meio ambiente, dos recursos naturais necessários a produção do bem de consumo em questão, até seu descarte final, logo após ter sido esgotado o uso para o qual este mesmo 
produto foi concebido, a ACV ganhou expressão rapidamente, muito embora seja uma técnica recente e que ainda necessita de ajustes metodológicos.

Um exemplo da envergadura desta expressão aparece retratado na ação empreendida pela International Organization for Standardization (ISO) que se decidiu - em 1996 - pela normatização e a padronização das práticas e condutas para a realização desses estudos.

As primeiras dessas normas - a ISO 14040 - definiram, entre outros elementos, os princípios básicos e requisitos para a realização e divulgação dos resultados de estudos de avaliação do ciclo de vida (MOURAD et. al. 2002).

Não obstante a padronização do conceito da ACV, a ISO 14040 estabeleceu quatros etapas para a realização do estudo (ABNT, 2009):

- Definição de objetivos e escopo;

- Análise do inventário;

- Avaliação dos impactos ambientais;

- Interpretação dos resultados.

O desenvolvimento minucioso desses estágios, que por essência da metodologia estão inter-relacionados, é fundamental para o êxito da $A C V$, evidenciando a abordagem holística dos impactos ambientais associados ao material de estudo.

Desta forma, a ACV se apresenta como uma ferramenta importante dentro dos sistemas de gestão, uma vez que discute com clareza e objetividade as questões ambientais relacionadas ao gerenciamento de recursos ambientais, à identificação de pontos críticos de processos e produtos, à otimização de sistemas e materiais e ao desenvolvimento de novas tecnologias.

\section{A INDÚSTRIA BRASILEIRA DE CERÂMICA}

A cerâmica para revestimento constitui um segmento da indústria de transformação, de capital intensivo, inserido na área de materiais não-metálicos. A atividade desse setor é responsável pela produção de materiais na forma de placas, usados na construção civil para revestimentos de paredes, pisos, bancadas e 
piscinas de ambientes internos e externos, os quais recebem diversas designações, tais como: azulejo, pastilha, porcelanato, grés, lajota, piso, entre outras.

De acordo com ANFACER (2009), o Brasil ocupa o segundo lugar em nível mundial entre mundial de produtores e consumidores de cerâmica para revestimentos, com capacidade instalada estimada em 713,4 milhões de $\mathrm{m}^{2}$ em 2009. Não obstante, o país foi o quinto maior exportador mundial do produto em 2008 , alcançando 305,4 milhões de $\mathrm{m}^{2}$ de revestimentos vendidos para o exterior.

O grupo de revestimentos é abordado com maior destaque em relação aos outros setores cerâmicos por se tratar de um segmento em expansão e com alto volume de consumo de matérias-primas. Segundo Motta, Zanardo e Junior (2001, p.33), mais de seis milhões de toneladas de matérias-primas são consumidos por ano pelo setor de revestimento. Tal consumo pode assim ser distribuído: $40-50 \%$ de argilas fundentes; $15-20 \%$ de argilas plásticas e caulim; $20-25 \%$ de outros minerais e rochas fundentes (filito, feldspato, talco carbonatos etc.); e até $5 \%$ de quartzo.

Tecnicamente, as placas cerâmicas podem ser produzidas por distintas combinações de matérias-primas e processos de produção. Destacam-se nesse contexto, fabricações por via seca e via úmida, cujas representatividades para o setor brasileiro foram, no ano passado, respectivamente de 69\% e 31\% (ANFACER, 2009).

Os produtos fabricados pelo processo de via úmida, considerados de melhor qualidade, são formulados usualmente com massa composta ou artificial constituída de argilas, caulim, filito, rochas feldspáticas, talco, carbonatos e quartzo, reunindo materiais fundentes, inertes e formadores de vidro. Tal mistura é moída e homogeneizada em moinhos de bola, em meio aquoso; seca e granulada em atomizadores; e conformada por prensagem a seco, para seguir então para a secagem, esmaltação e sinterização (Associação Brasileira de Cerâmica, 2009).

A fim de identificar as deficiências da cadeia produtiva de revestimentos cerâmicos, o Centro Cerâmico do Brasil (CCB) e o Instituto de Pesquisas Energéticas e Nucleares (IPEN), desenvolveram conjuntamente 0 Projeto Plataforma. Neste, foram verificados problemas tecnológicos que permeiam toda a 
cadeia, assim como outros específicos que abrangem essencialmente o processo de fabricação de cerâmicos e revestimentos.

Gorini e Correa (2009) relacionam dentre as principais dificuldades de fundo técnico-processuais, econômico e ambiental vividas pela indústria cerâmica: processamentos relativos à etapa de mineração de minerais inorganicos; inexistência de uma metodologia racional para a formulação de massas e, por conseguinte, falta de uniformidade; controle deficiente de recebimento de matériaprima; variações físicas e defeitos diversos no produto; ausência de planejamento e controle de produção; deficiências de base gerencial do processo; falta de especificação e mão-de-obra qualificada na construção civil; inexistência de metodologias de aplicação e manutenção do produto.

Segundo os mesmos autores, além dos aspectos já citados merecem também especial atenção dentro do mesmo segmento a falta de monitoramento, prevenção e controle dos resíduos; custos elevados dos projetos de recuperação ambiental, controle e prevenção de poluição atmosférica; e, uso de medidas paliativas e ineficientes para atendimento à legislação ambiental (GORINI; CORREA, 2009).

\section{CARACTERIZAÇÃo DA ROTA TECNOLÓgICA DE PROCESSAMENTO DE PORCELANATO ESMALTADO}

Segundo Oliveira (2000), além da natureza química e das associações mineralógicas das matérias-primas, as características finais de um produto cerâmico dependem fortemente dos parâmetros tecnológicos adotados durante o processo produtivo. De acordo com Quinteiro et al. (1995) o processo via úmida apresenta maior qualidade do produto final, o que justifica seu uso para o processo de fabricação de revestimentos como o porcelanato. Neste sentido, Motta, Zanardo e Junior (2001, p.35) reforçam que os revestimentos de via úmida são de base preferencialmente clara, formulados com massa composta ou artificial, que é constituída de argilas, caulim, filito, rochas feldspáticas, talco, carbonatos e quartzo, que reúnem os materiais fundentes, inertes e formadores de vidro. 
Segundo os mesmos autores, a mistura é moída e homogeneizada em moinhos bola, em meio aquoso; seca e granulada em spray dryer (atomizador); e conformada por prensagem a seco, para seguir então para a decoração e queima.

Pereira (2004, p.39) descreve a tecnologia do processamento de porcelanato esmaltado como o encadeamento dos seguintes processos:

A moagem por via úmida tem por objetivo diminuir o tamanho das partículas das matérias-primas envolvidas no processo e garantir a homogeneização da massa cerâmica dentro de uma distribuição granulométrica definida. Para o processo de fabricação do porcelanato, comumente são utilizados moinhos do tipo bola, por onde a massa é introduzida em cilindros que contêm seixos de tamanhos variados. A movimentação desses seixos no interior do moinho ocorre por rotação, produzindo a moagem por choque e atrito com o material a ser moído. Nessa etapa deve-se ter controle sobre a velocidade de rotação, no intuito de garantir a granulometria desejada da barbotina, produto resultante desta etapa do processo que consiste das matérias-primas sólidas e água.

A atomização é o processo pelo qual ocorre a evaporação parcial da água contida na barbotina, formando o pó atomizado. Nesta etapa a barbotina é bombeada para um sistema dispersor, localizado no interior de uma câmara de secagem ventilada com ar aquecido a uma temperatura média de 500 a $600^{\circ} \mathrm{C}$. A pulverização da barbotina em meio ao ar quente proporciona a evaporação quase instantânea da água, bem como, a formação de pequenas e arredondadas partículas. Os granulados secos resultantes são separados do ar quente e úmido para posterior utilização.

A prensagem consiste na conformação do pó atomizado, com vistas à formatação da peça cerâmica. O revestimento verde, ou biscoito, é a principal saída do processo, possuindo um teor de umidade próximo ou igual ao do pó atomizado. Segundo Pereira (2004), a pressão média exercida sob o pó varia entre 20 e $50 \mathrm{Mpa}$ de 200 a $\left.500 \mathrm{~kg} / \mathrm{cm}^{2}\right)$. Tal pressão tem por objetivo deformar e realocar as partículas contidas na massa gerando um produto compactado e cru.

A operação de secagem é um processo térmico que visa à redução da quantidade de água existente no revestimento verde. Ao final do processo o 
revestimento seco sai com conteúdo de água usualmente inferior a $1 \%$ do peso da massa. Conforme coloca Oliveira (2008), o calor de secagem é fornecido principalmente por queimadores a gás natural, atingindo temperaturas médias de $170^{\circ} \mathrm{C}$. É fundamental nesta etapa que a secagem ocor ra de maneira rápida, para aumentar a eficiência do sistema e reduzir o consumo de energia para aquecimento do ar.

O acabamento superficial do porcelanato é realizado na etapa de esmaltação, a partir de fritas cerâmicas de natureza vítrea que recobrem a superfície da peça suporte. O esmalte é composto de matérias-primas como caulim, areia, óxidos diversos, pigmentos, fritas, entre outros materiais que podem ser adicionados secos ou ainda com teor de água na ordem de 40\% (PEREIRA, 2004). O processo de esmaltação é efetuado por uma linha contínua de máquina para aplicação, obtendose no final do processo o revestimento com esmalte cru. Nesta etapa, são gerados resíduos de produção incluindo-se fundamentalmente sobras de revestimentos.

A sinterização compreende a etapa final do processo de produção do porcelanato. Nela, o revestimento esmaltado adquire características mecânicas e estabilidade química para usos específicos. Segundo Oliveira (2000), a temperatura de queima pode variar entre $1000-1100^{\circ} \mathrm{C}$ conforme o tipo de frita.

Durante o processo de sinterização, são verificadas reações e transformações como a eliminação total da água, combustão de substâncias orgânicas, transformação do quartzo, colapso da retícula dos minerais argilosos, decomposição do carbono, dentre outras reações que conferem ao revestimento as características físico-mecânicas, dureza e compactação.

Emissões gasosas provenientes da queima, bem como resíduos de peças que por conseqüência do processo foram danificadas, são as principais perdas do processo, que resulta no porcelanato queimado e esmaltado.

\section{AVALIAÇÃO DO CICLO DE VIDA DO PORCELANATO ESMALTADO}

O estudo das atividades compreendidas na obtenção dos recursos naturais até a fabricação do porcelanato esmaltado, ao final de toda a cadeia produtiva, foi 
fundamentado na padronização metodológica apresentada pela ISO 14040 para estudos de Avaliação do Ciclo de Vida, que se segue abaixo conceituada (ABNT, 2001).

\section{- Definição de Objetivos}

O objetivo do presente estudo de Avaliação do Ciclo de Vida consiste em proceder a uma análise do desempenho ambiental do atendimento da função recobrir certa área com porcelanato, com vista à proposição de medidas de diferentes procedências as quais tornem o atendimento de tal necessidade menos impactante ao meio ambiente.

\section{- Definição do Escopo}

O desenvolvimento predispôs que fossem estabelecidos os requisitos técnicos que se seguem:

a) Função: recobrir uma área de circulação por 20 anos

b) Unidade Funcional: $100 \mathrm{~m}^{2}$ de piso de circulação por 20 anos;

c) Coeficiente de desempenho técnico: considerando que o material a ser empregado no atendimento da função supracitada é o porcelanato recoberto com esmalte, tem-se que $\rho=19 \mathrm{~kg} / \mathrm{m}^{2}$.

d) Fluxo de Referência (FR): dadas a unidade funcional (UF) antes definida e o coeficiente de desempenho técnico $(\rho)$, tem-se que:

$$
F R=19\left[\mathrm{~kg} / \mathrm{m}^{2}\right] \times 100\left[\mathrm{~m}^{2}\right]=1900 \mathrm{~kg}
$$

e) Fronteiras do Sistema de Produto: dados os objetivos a que se propõe esta iniciativa, o modelo adotado de sistema de produto obedece a uma abordagem do tipo "berço-ao-portão da fábrica". Assim sendo, passaram a constituir o Sistema de Produto em estudo, na qualidade de processos elementares: transporte de matérias-primas desde a mina até a unidade de produção; moagem e classificação do material; atomização; prensagem; secagem; esmaltação; sinterização; classificação; produção de gás natural e de energia elétrica. 
A Figura 1 descreve a tecnologia de processamento de materiais cerâmicos pela via úmida, adotada para fins de desenvolvimento da presente iniciativa.

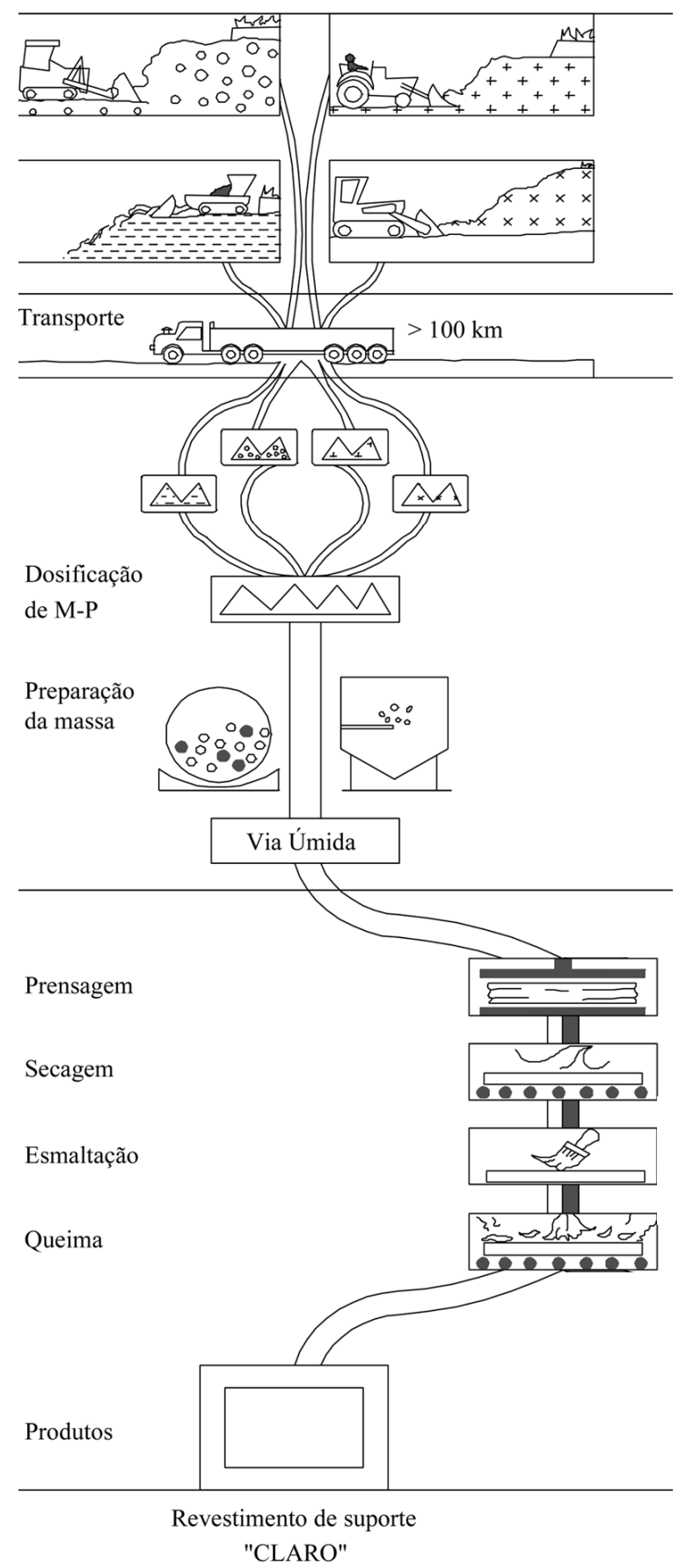

Figura 1 - Fluxograma do processo de produção de revestimentos prensados Fonte: Adaptado de Motta; Zanardo; Junior (2001)

Deve-se evidenciar que as cargas ambientais associadas à extração em si das matérias-primas minerais foram desconsideradas para efeito da presente Revista Produção Online, v.10, n.4, p. 912-936, dez., 2010 
avaliação uma vez que suas contribuições foram avaliadas como pouco significantes em termos quali-quantitativos pela aplicação dos critérios de exclusão de massa, energia e relevância ambiental empregados no estudo. Analogamente, os dados que retratam aspectos ambientais associados a produção e ao transporte de gás natural e de energia elétrica foram coletados junto ao Balanço Energético Nacional (BEN, 2007);

f) Procedimento de Alocação: não foram considerados para o caso presente quaisquer procedimentos de alocação.

g) Seleção do Modelo de Avaliação de Impacto: definiu-se como modelo de Avaliação de Impacto (Al) mais adequado para esta abordagem o EcoIndicator 99 com pacotes de normalização e de valoração do tipo Egalitarian Perspective (E/E).

h) Cobertura Geográfica: considerou-se como cobertura geográfica os estados de Paraná, Rio Grande do Sul e Santa Catarina.

i) Cobertura temporal: foram empregados dados e informações datados de 2008-2009, medidos ao longo de um período de 4 (quatro) meses.

j) Cobertura Tecnológica: foram coletados junto ao processo que pratica tecnologia de produção de porcelanato por via úmida.

\section{ELABORAÇÃO DO INVENTÁRIO DE CICLO DE VIDA (ICV)}

A partir da definição dos objetivos e escopo, bem como das etapas de produção do porcelanato branco esmaltado em estudo, é possível estabelecer o inventário de consumos e descartes associados à fabricação das peças em questão e determinar as considerações necessárias para a avaliação do ciclo de vida.

\subsection{Extração e Transporte de Matérias-Primas}

A extração das matérias-primas utilizadas tanto para a obtenção da barbotina quanto para a fabricação do esmalte tem origem nos estados que se seguem: Paraná, Rio Grande do Sul e Santa Catarina. 
Pelos motivos já comentados na caracterização dos procedimentos de definição de objetivos e escopo, os aspectos ambientais associados à extração desses materiais não foram aportados neste estudo. Para o caso do transporte desses mesmos materiais - que a posteriori, serão utilizados para a fabricação da barbotina - foram consideradas para efeito de avaliação apenas as distâncias do percurso de ida das jazidas até a fábrica. Isto porque, tomou-se por premissa para essa modelagem que os caminhões utilizados nesse deslocamento retornem da unidade produtiva até as cidades de origem das jazidas transportando outros bens de consumo.

No que tange ao transporte das matérias-primas do esmalte, este foi desconsiderado na realização deste trabalho, tendo em vista a pequena quantidade em massa deste material incorporada no revestimento acabado.

\subsection{Determinação de Perdas}

Para o desenvolvimento do balanço material e quantificação das entradas e saídas para a produção da unidade funcional, foi realizado o levantamento de perdas do processo.

As perdas foram contabilizadas de maneira a se obter a porcentagem de material rejeitado ou quebrado com relação à quantidade de material produzido em cada etapa. Concluído tal levantamento foi então possível elaborar um diagrama generalizado do processo produtivo em estudo, o qual aparece representado a seguir na Figura 2.

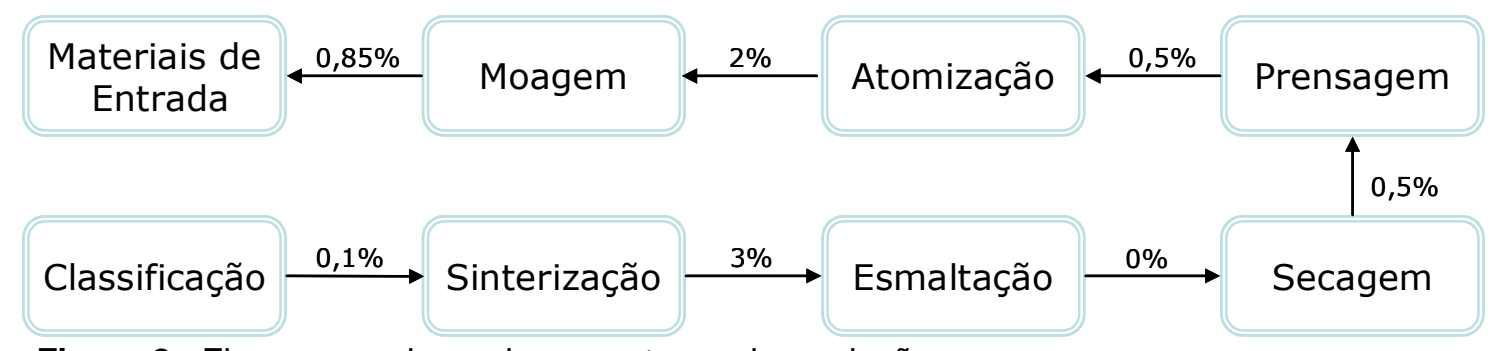

Figura 2 - Fluxograma de perdas nas etapas de produção.

Fonte: Elaborado pelo autor 


\subsection{Moagem e Classificação}

O processo de moagem das matérias-primas acontece por meio de moinhos bola. Nesta etapa a perda de processo é aproximadamente de $0,85 \%$ e a quantidade de água adicionada para a formação da barbotina representa $35,4 \%$ do produto final desta etapa.

O resíduo gerado no processo sai com umidade igual a da barbotina, retornando para o processo de moagem, sem que haja disposição final desses resíduos. Ainda, tem-se como entrada na etapa de moagem, o pó recuperado pelos filtros mangas durante a atomização da barbotina e o resíduo sólido gerado na etapa de prensagem, cujas características estarão descritas nos itens referentes a cada etapa referida.

O consumo de energia para a etapa de moagem e classificação é de origem elétrica da rede de distribuição pública, utilizado para partida e operação das máquinas.

A partir de dados primários cedidos por uma organização do setor cerâmico, elaborou-se o esquema indicado na Figura 3, em que estão ilustradas correntes de entrada e saída, de matéria e de energia, consumidas e geradas na moagem.

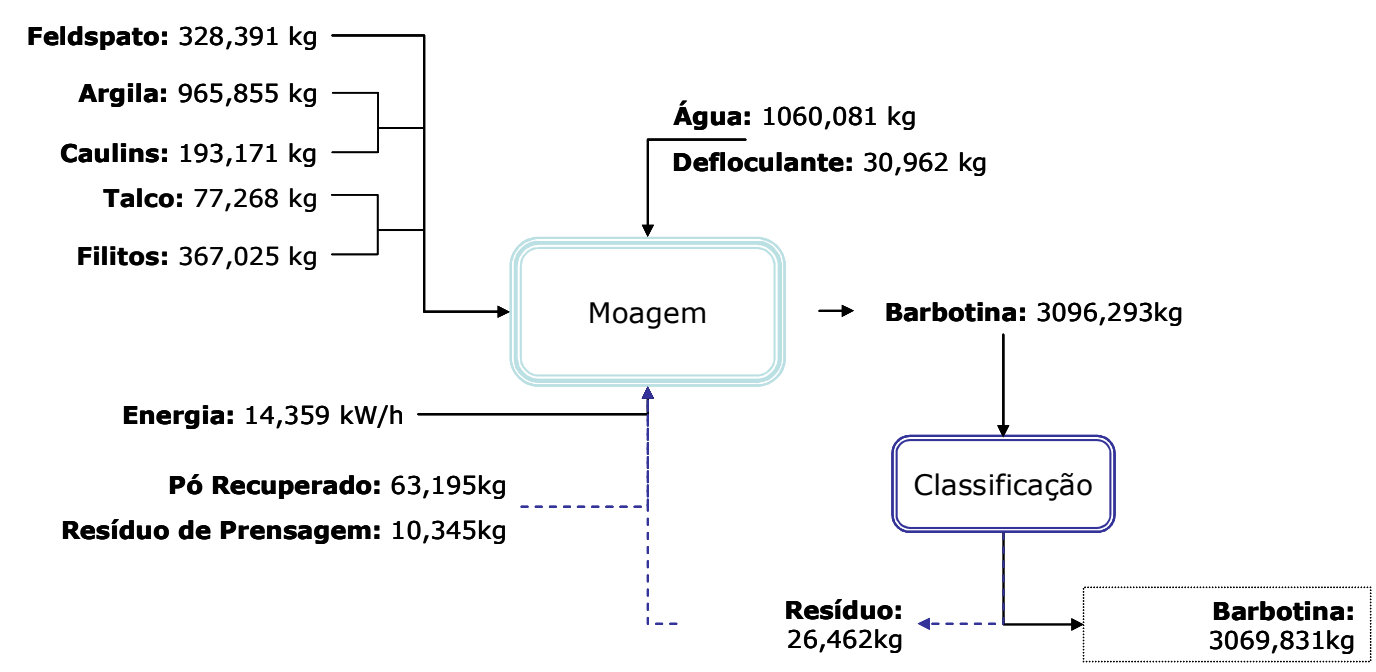

Figura 3 - Fluxograma de entradas e saídas do processo de moagem e classificação Fonte: Elaborado pelo autor 


\subsection{Atomização}

O processo de atomização produz em média 9,5 toneladas de pó atomizado por hora, com uma perda de cerca de $2 \%$ do material de saída. Desta perda, $0,5 \%$ é emitido para a atmosfera em forma de material particulado e o restante retorna para o processo de moagem como pó recuperado. Para essa quantidade de material produzido o consumo médio de gás natural registrado é de $662,4 \mathrm{~m}^{3}$ e o de energia elétrica da rede é de $100 \mathrm{kWh}$.

Para a realização do balanço foi considerada uma entrada de ar suficiente para que ocorresse a combustão completa do gás natural, desconsiderando qualquer condensação de água. Ao final do processo, o pó atomizado sai com umidade próxima a $6 \%$, como pode ser observado no diagrama apresentado pela Figura 4 em que aparecem detalhadas correntes de matéria e de energia que circulam pelo processo de atomização.

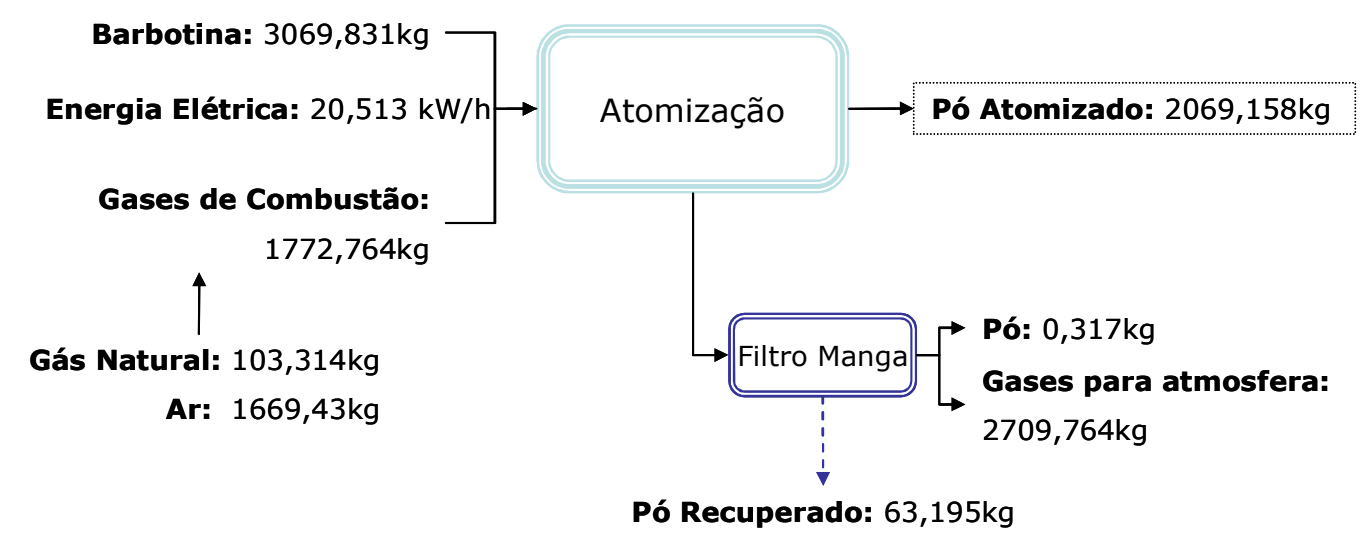

Figura 4 - Fluxograma de entradas e saídas do processo de atomização Fonte: Elaborado pelo autor

\subsection{Prensagem}

Nesta etapa de produção são formatadas as peças de porcelanato sem que haja perda de água por pressão do pó atomizado. A prensagem acontece por mecanismos hidráulicos que funcionam com o uso de energia elétrica da rede de distribuição pública.

Revista Produção Online, v.10, n.4, p. 912-936, dez., 2010 
A perda média de material registrada pelo setor em função de quebra ou deformação é de $0,5 \%$. Assumiu-se que esse material não será, no entanto, disposto no meio ambiente, sendo sim reintegrado ao processo na etapa de moagem. A Figura 5 traz, de maneira sintética, um diagrama de blocos característico do processo elementar de prensagem, destacando as principais correntes materiais e energéticas de entradas e saídas.

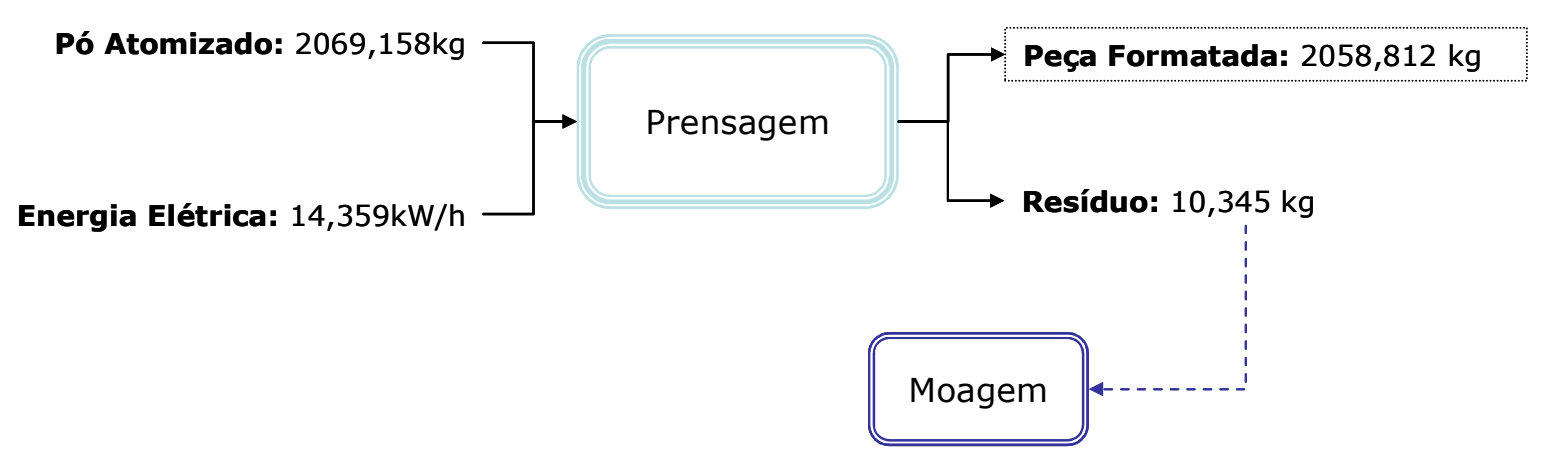

Figura 5 - Fluxograma de entradas e saídas do processo de prensagem Fonte: Elaborado pelo autor

\subsection{Secagem}

A umidade da peça na saída do secador é de $0,01 \%$ e a quebra de produção nesta etapa, principalmente por danos causados no transporte, é de $0,5 \%$.

A partir desta etapa, todo o resíduo sólido gerado é encaminhando para disposição final, não sendo reaproveitado no processo.

O consumo de gás natural para secagem é de aproximadamente $53 \mathrm{~m}^{3}$ para uma produção de 9,4 toneladas de porcelanato, sendo $\circ$ ar necessário para combustão calculado para que esta ocorra de maneira plena. Ainda, para o transporte das peças por esteiras são consumidos $55 \mathrm{kWh}$ de energia elétrica, considerando a mesma base de material produzido acima indicada. No intuito de ilustrar as principais correntes de entradas e saídas da etapa de secagem, aparece abaixo indicado na Figura 6, um fluxograma genérico do referido processo elementar. 


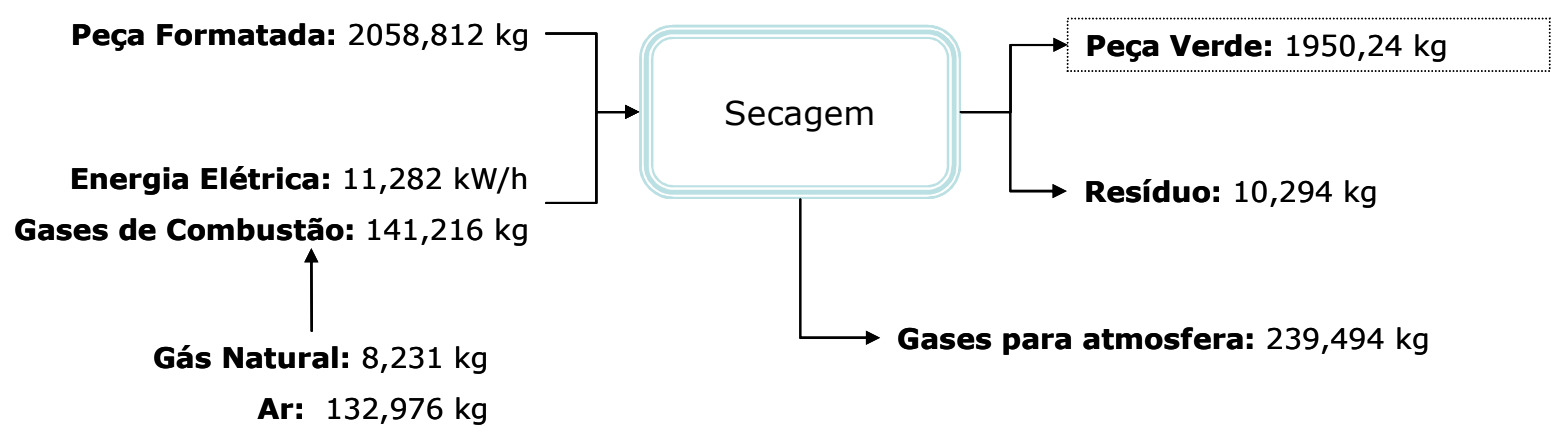

Figura 6 - Fluxograma de entradas e saídas do processo de secagem Fonte: Elaborado pelo autor

\subsection{Esmaltação}

Para a realização do perfil ambiental do porcelanato foi adotada a composição do esmalte branco comumente utilizado pelo setor cerâmico. Os principais componentes e suas respectivas quantidades, já previamente ajustados à unidade funcional definida para o estudo, aparecem representados a seguir no diagrama indicado na Figura 7.

A perda de peças esmaltadas ao final desta etapa foi nula durante todo o período de coleta de informações, havendo um incremento de $1,96 \%$ ao peso do revestimento seco por conta da adição de esmalte de cobertura. Note-se, por fim, que a produção de $9,5 t$ de porcelanato esmaltado resulta em um consumo médio de 22KWh de energia elétrica. 


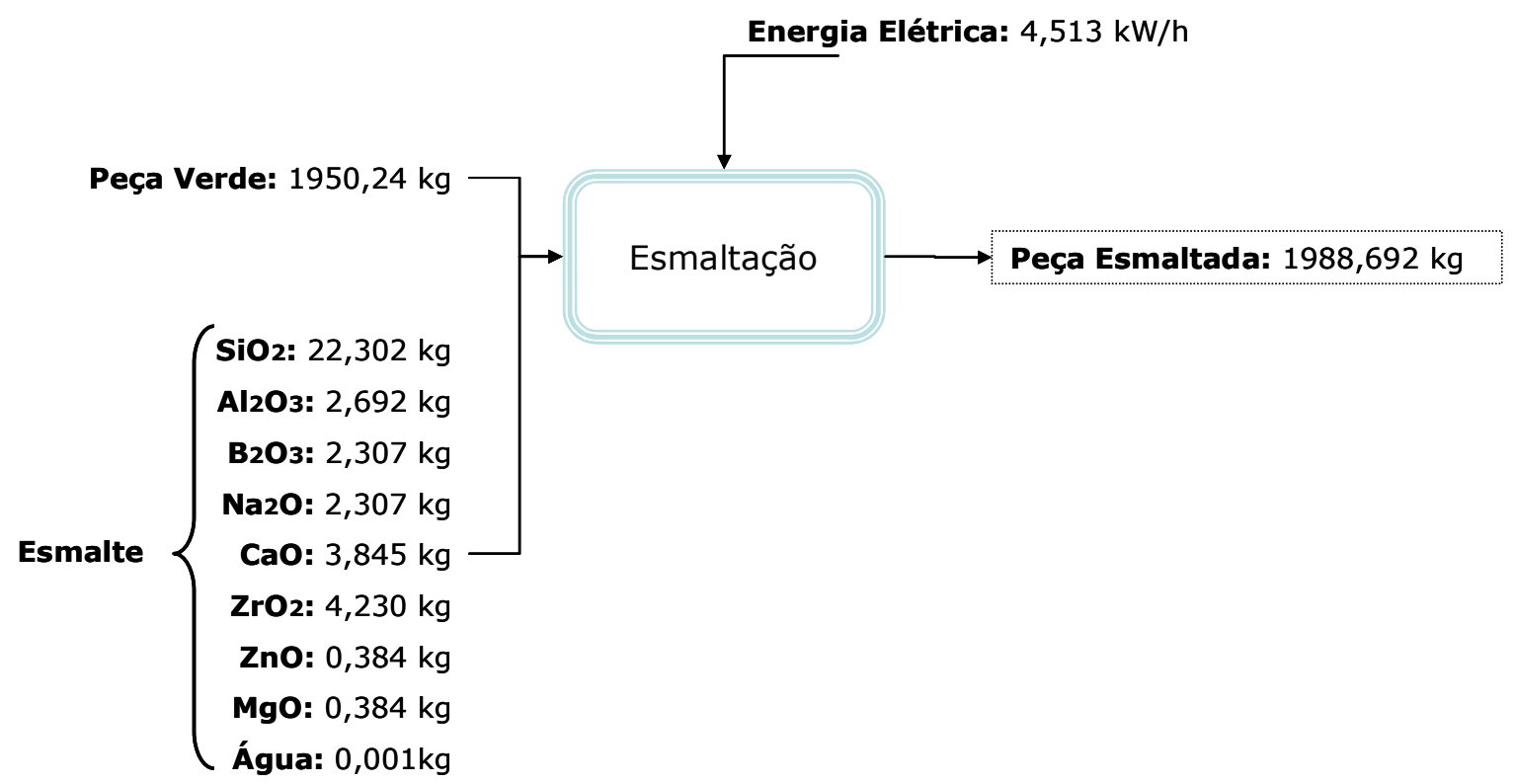

Figura 7 - Fluxograma de entradas e saídas do processo de esmaltação

Fonte: Elaborado pelo autor

\subsection{Sinterização}

Os fornos utilizados para a queima, com base na tecnologia de produção da planta estudada, são do tipo contínuo abastecidos por gás natural. Estes fornos apresentam um consumo de gás natural de aproximadamente $35 \mathrm{~kg}$ para a produção da unidade funcional de porcelanato. Para a obtenção das quantidades de gases emitidos no processo de combustão foi realizado um balanço estequiométrico considerando a combustão completa do gás natural, sem que haja, no entanto, condensação do vapor d'água.

Ao final do processo, o revestimento esmaltado sai sem umidade, sendo a perda ponderada desta etapa de $3 \%$ do material de saída, como pode ser observado mais adiante no diagrama constituído pela Figura 8. 


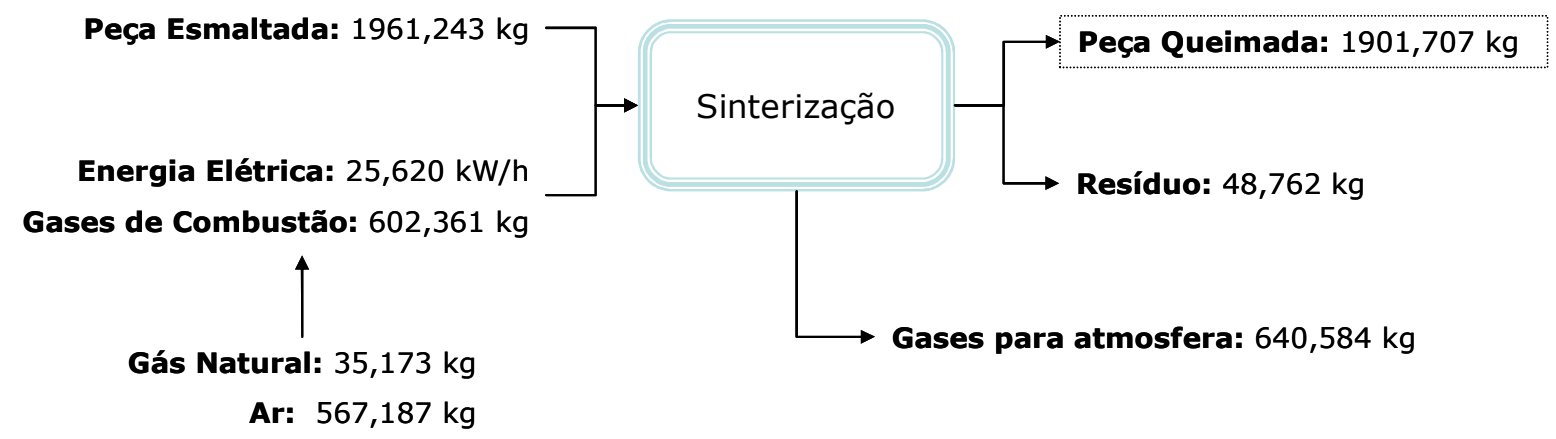

Figura 8 - Fluxograma de entradas e saídas do processo de sinterização Fonte: Elaborado pelo autor

\subsection{Classificação}

Após a sinterização, as peças acabadas são transferidas para uma esteira onde são classificadas manualmente por uma equipe técnica. Cerca de $1 \%$ das peças são reprovadas ou sofrem danos no transporte, sendo dispostas como resíduo sólido.

Segundo levantamentos efetuados junto ao processo, na etapa de transformação em referência, o consumo energético da esteira é de $15 \mathrm{KWh}$ para uma quantidade de material transportado de 9,0 toneladas. A Figura 9 mostra 0 conjunto de correntes de entrada e de saída da classificação de material.

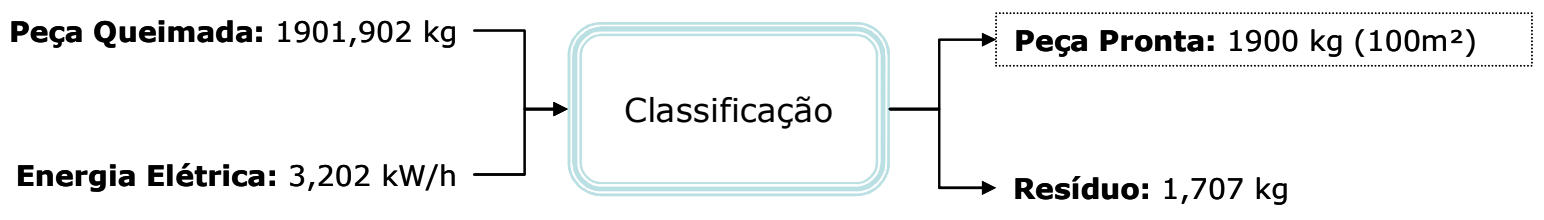

Figura 9 - Fluxograma de entradas e saídas do processo de classificação

Fonte: Elaborado pelo autor

\section{RESULTADOS E DISCUSSÃo}

A produção da unidade funcional de $100 \mathrm{~m}^{2}$ de porcelanato branco esmaltado, nas condições pré-estabelecidas pelo escopo deste trabalho, é responsável pelo 
consumo de matérias-primas, energia e geração de resíduos, o que, por conseguinte, acarreta em uma série de impactos ambientais.

No sentido de obter o perfil ambiental do produto em questão, foram produzidas tabelas e desenhos sobre seu ciclo de vida, por meio do uso do software Simapro 7.1. Nestes foram verificadas as influências das etapas do sistema produtivo em cada categoria de impacto que se segue: depleção abiótica, acidificação, eutrofização, aquecimento global, depleção da camada de ozônio, toxicidade humana, ecotoxicidade e oxidação fotoquímica.

O Perfil de Desempenho Ambiental do porcelanato branco esmaltado produzido pela via úmida, gerado a partir das condicionantes que balizam o estudo, aparece representado a seguir na Tabela 1.

Com base nas informações acima descritas, é possível verificar que os impactos ambientais mais expressivos do processo de fabricação do porcelanato são o aquecimento global e a toxicidade humana, não apresentando, assim, um perfil de impacto diversificado. 
Tabela 1 - Perfil de Impacto Ambiental do Porcelanato Branco Esmaltado

\begin{tabular}{|c|c|c|c|c|}
\hline Categoria de Impacto & Unidade & Total & $\begin{array}{c}\text { Porcelanato } \\
\text { branco } \\
\text { esmaltado }\end{array}$ & $\begin{array}{c}\text { Produção } \\
\text { de }\end{array}$ \\
\hline Depleção Abiótica & $\mathrm{kg} \mathrm{Sb} \mathrm{eq}$ & 9,308 & 9,305 & 0,002 \\
\hline Acidificação & $\mathrm{kg} \mathrm{SO}_{2} \mathrm{eq}$ & 3,024 & 3,023 & 0,001 \\
\hline Eutrofização & $\mathrm{kg} \mathrm{PO} 4 \mathrm{eq}$ & 0,418 & 0,418 & 0,000 \\
\hline Aquecimento Global & $\mathrm{kg} \mathrm{CO} 2 \mathrm{eq}$ & 789,674 & 788,989 & 0,686 \\
\hline $\begin{array}{c}\text { Depleção da Camada de } \\
\text { Ozônio }\end{array}$ & $\begin{array}{l}\text { kg CFC-11 } \\
\text { eq }\end{array}$ & 0,000 & 0,000 & 0,000 \\
\hline Toxicidade Humana & kg 1,4-DB eq & 163,159 & 163,063 & 0,096 \\
\hline Ecotoxicidade & kg 1,4-DB eq & 0,877 & 0,872 & 0,004 \\
\hline Oxidação Fotoquímica & $\mathrm{kg} \mathrm{C}_{2} \mathrm{H}_{4}$ & 0,150 & 0,150 & 0,000 \\
\hline
\end{tabular}

Fonte: Elaborado pelo autor

Tendo em vista os dados referenciados na Tabela 1 foi possível constatar que a partir das condições em que o presente estudo foi conduzido, não foram identificados impactos ambientais em termos de Depleção da Camada de Ozônio.

No que tange ao Aquecimento Global, categoria de impacto de maior significância, é possível verificar que mais de $50 \%$ do impacto é ocasionado pelo uso de gás natural das etapas de atomização, secagem e sinterização do porcelanato. Isto porque, é nesses processos que se concentra majoritariamente, o consumo de energia fabril do setor cerâmico, o que permite uma grande gama de possibilidades para a implantação de medidas de redução de impacto por parte da indústria.

De acordo com Oliveira (2008), é condição fundamental para a redução do consumo energético que a secagem ocorra de maneira rápida, eficiente e de baixo desperdício, controlando as taxas de aquecimento, circulação de ar, temperatura e umidade. Ademais medidas para reaproveitamento do ar quente entre etapas do processo produtivo, podem resultar em reduções significativas no consumo de combustíveis.

Não obstante, ainda sobre os resultados obtidos de aquecimento global, temse que $28 \%$ do impacto são ocasionados pela fabricação e manutenção dos veículos utilizados para o transporte das matérias-primas, dado que a extração desses materiais encontra-se a distâncias de 400 a 600 quilômetros da planta de produção 
do porcelanato estudada, o que acaba por exigir constantes trabalhos de revisão dos veículos.

No quesito toxicidade humana, um montante de $95 \%$ do impacto é ocasionado pelo processo de fabricação e manutenção dos veículos de transporte de matérias-primas, mais especificamente pelas atividades secundárias fundamentais para a realização desses processos. Dentre essas atividades tem-se a construção de poços para exploração e produção de combustíveis, fabricação de materiais como plástico, óleo, alumínio, dentre outros. Essa análise permite verificar que no que refere à toxicidade humana, o processo de fabricação do porcelanato apresenta um campo de ação limitado, uma vez que todas as atividades relacionadas aos veículos utilizados para transporte da matéria-prima são de difícil controle por parte da indústria cerâmica.

Não obstante, vale ressaltar que para os fins do presente estudo, a escolha do transporte teve-se no pacote de dados Ecoinvent - versão 2.0 -, sendo selecionado de maneira a representar, de maneira mais próxima, a realidade dos veículos usados pela indústria de cerâmica em estudo.

A depleção de recursos abióticos, dada as condições e limitações deste estudo, decorre essencialmente pela produção de gás natural utilizado no processo produtivo e pelo óleo usado para a fabricação e manutenção dos veículos. Contudo, ressalta-se que aproximadamente $73 \%$ deste impacto decorrem da extração do gás natural, segundo a matriz de distribuição brasileira adotada.

Neste sentido, assim para o caso de aquecimento global antes mencionado, ações de melhoria do processo produtivo que derivem em redução da demanda de combustível podem ocasionar na redução deste impacto, na medida em que evitam a extração de recursos abióticos.

Para as categorias de impacto restantes - acidificação, depleção da camada de ozônio, eutrofização, ecotoxicidade e oxidação fotoquímica -, observa-se que o grau de significância pouco aporta, de uma forma mais abrangente, para o impacto ambiental gerado pelo processo de fabricação do porcelanato branco esmaltado. Ainda, é verificado de maneira similar à toxicidade humana, que tais impactos são 
fundamentalmente decorrentes de processos secundários para a fabricação e manutenção dos veículos.

Esta análise é bastante interessante, pois demonstra que, dependendo da categoria de impacto analisada, uma etapa do processo produtivo poderá ser mais ou menos impactante do que o outro.

\section{CONCLUSÕES}

A avaliação do perfil ambiental do porcelanato branco esmaltado permitiu vislumbrar de maneira efetiva o peso de cada etapa do processo produtivo no que tange aos impactos ocasionados ao meio ambiente em todo o ciclo de vida estudado, ou seja, do "berço-ao-portão da fábrica".

Muito embora este estudo tenha avaliado apenas um produto por uma linha de produção específica, os resultados obtidos pela análise constituem uma realidade muito próxima da verificada nas indústrias cerâmicas de fabricação de porcelanato, podendo ser adaptado para a realização de outros estudos do setor.

No que se refere às categorias de impactos, pode-se concluir que as medidas de produção mais limpa devem estar direcionadas no sentido de minimizar, principalmente, a potencialidade do aquecimento global e da toxicidade humana.

Ainda, verifica-se que a maior parte dos impactos ambientais ocasionados pelo processo produtivo são decorrentes do consumo de gás natural e do transporte utilizado para a locomoção das matérias-primas. Essas constatações direcionam de maneira evidente a tomada de decisão para a alteração do processo produtivo ou até mesmo para alteração de locais de extração de matérias-primas, a fim de reduzir o uso do transporte.

O desenvolvimento de medidas que tornem mais eficiente à geração de ar quente, que reduzam a perda de material no processo, que aperfeiçoem os parâmetros operacionais, ou que visem à substituição do combustível para fontes mais limpas, são algumas das ações de redução de impacto que podem ser estudadas a fim de se verificar a sua influência no perfil ambiental do porcelanato esmaltado. 
Desta forma, poder-se-á aferir quantitativamente a alteração dos resultados simulados para cada categoria de impacto, corroborando para um movimento de melhoria de desempenho ambiental do setor cerâmico.

Enfim, neste contexto, sugere-se que novos estudos sejam realizados de maneira completar de modo a se averiguar os benefícios ambientais e até mesmo econômicos da adoção de medidas de produção mais limpa para revestimentos cerâmicos.

\section{REFERÊNCIAS}

ASSOCIAÇÃO BRASILEIRA DE NORMAS TÉCNICAS. NBR ISO 14040 - Gestão ambiental - Avaliação do ciclo de vida - Princípios e estrutura. Rio de Janeiro: ABNT, 2009.

ASSOCIAÇÃO NACIONAL DE FABRICANTES DE CERÂMICA PARA REVESTIMENTO. Estatísticas do setor: anuário eletrônico 2008. Disponível em: $<$ http://www.anfacer.org.br/>. Acesso em: 31 maio 2009.

BRASIL. Balanço energético nacional - BEN. Brasília: Ministério de Minas e Energia, 2007.

FERRARI, K. R. Aspectos ambientais do processo de fabricação de placas de revestimentos cerâmicos (via úmida), com ênfase nos efluentes líquidos. 2000. Tese (Doutorado) - Instituto de Pesquisas Energéticas e Nucleares - IPEN, 2000.

INTERNATIONAL ORGANIZATION FOR STANDARDIZATION. Environmental management: life cycle assessment: examples of application of ISO 14042 / Management environmental: ISO 14047, Draft Technical Report. Genéve, 2000c.

MOTTA, J. F.; ZANARDO, A., JUNIOR, M. C. As matérias-primas cerâmicas. Parte I: O perfil das principais indústrias cerâmicas e seus produtos. Cerâmica Industrial, São Paulo, v. 6, n. 2, p. 28-40, 2001.

MOURAD, A. L.; GARCIA, E. C.. Avaliação do ciclo de vida: princípios e aplicações. Campinas: CETEA/CEMPRE, 2002.

OLIVEIRA, A. P. N. de. Tecnologia de fabricação de revestimentos cerâmicos. Cerâmica Industrial, São Paulo, v. 5, n. 6, p. 37-48, 2000.

OLIVEIRA, M. C. Guia técnico ambiental da indústria de cerâmicas branca e de revestimentos. São Paulo: CETESB, 2008. 
PEREIRA, S. W. Análise ambiental do processo produtivo de pisos cerâmicos. Aplicação de avaliação do ciclo de vida. 2004. f.122. Dissertação (Mestrado em Engenharia Ambiental) - Universidade Federal de Santa Catarina. Florianópolis, 2004.

QUINTEIRO, E.; CASTRAL JR., J.; PINATTI, A. \& BOSCHI, A. O. Estudo comparativo de massas de revestimento para processamento via seca e via úmida. In: CONGRESSO BRASILEIRO DE CERÂMICA. 39. 1995. Anais. Águas de Lindóia : p.434-439, 1995.

VILELA, A.; DEMAJOROVIC, J.(orgs.). Avaliação do ciclo de vida. In: Modelos e ferramentas de gestão ambiental: desafios e perspectivas para as organizações. São Paulo: SENAC, 2006.

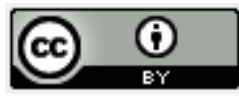

Artigo recebido em 22/12/2009 e aceito para publicação em 26/08/2010. 